\title{
BIM PARA A REPRESENTAÇÃO FÍSICA DE EDIFICAÇÃO EXISTENTE: ESTUDO DE CASSO NO INSTITUTO MARIA
}

\author{
Maria Aparecida Hippert ${ }^{(1)}$, Beatriz Henriques ${ }^{(1)}$, Charles Pereira ${ }^{(1)}$, Larissa Silva ${ }^{(1)}$, \\ Patrick Farinati ${ }^{(1)}$
}

(1)Universidade Federal de Juiz de Fora, Juiz de Fora

\begin{abstract}
Resumo
O Instituto Maria é uma instituição filantrópica que oferece de forma gratuita formação às crianças desprovidas material e socialmente. Localizado na cidade de Juiz de Fora/MG/Brasil numa área de $3000 \mathrm{~m}^{2}$ completou, em março de 2019, 75 anos de sua fundação. A representação física do espaço está disponível de forma impressa em papel vegetal com data de 2006 e de lá para cá, algumas reformas foram realizadas. O objetivo deste artigo é apresentar o projeto desenvolvido para atualização da representação física do Instituto de maneira a retratar a realidade atual, usando o BIM. A metodologia considerou a realização de treinamento dos alunos no uso do Revit, levantamento em campo e representação gráfica. Na medida em que os dados iam sendo levantados eles eram tranpostados para o Revit. Este procedimento foi adotado de maneira que as inconsistências, porventura encontradas em virtude da grande área física a ser levantada, pudessem ir sendo verificadas e resolvidas ao longo do processo de representação. Resultados obtidos apontam que a representação em BIM ao invés do CAD se mostrou mais eficiente, sendo o processo, as dificuldades e vantagens encontradas ao longo de seu desenvolvimento apresentadas neste trabalho. A partir do projeto as-built de arquitetura espera-se realizar, também, a modelagem dos projetos das demais especialidades de maneira a contribuir para a realização das atividades de manutenção deste espaço físico.
\end{abstract}

\section{Introdução}

O tema manutenção de edifícios tem crescido de importância na atualidade. Isto por que com o passar do tempo, materiais e edificações se deterioram e precisam passar por atividades de manutenção de maneira a atender às condições de desempenho estabelecidas inicialmente no projeto.

Para Terror [1], "Edifícios são obras arquitetónicas apenas; se habitados por pessoas são lares; se habitados, também por ideias, são mais do que lares, são Escolas. Entretanto, quando o tempo os torna inadequados para o uso, são presas fáceis da obsolescência e estão condenados a condição de meras ruínas". Daí a importância de se manter os espaços utilizáveis. 
As atividades de operação e manutenção $(\mathrm{O} \& M)$ são realizadas na fase de uso da edificação. Elas se referem à realização de trabalhos visando à manutenção, ao restauro e ao melhoramento de todas as partes, subsistemas, serviços e arredores de um edifício a fim de sustentar sua utilidade e valor [2].

A utilização do Building Information Modeling (BIM) nas atividades de O\&M começa a surgir; ele pode contribuir para otimizar a manutenção, exportando as informações da edificação e de equipamentos para o sistema que será utilizado [3]. Porém, o BIM vem sendo utilizado, de maneira geral, para os novos edifícios, sendo ainda pequena sua implementação em edificações existentes [4][5].

Para Eastman [3], o nível de maturidade da implantação de BIM na manutenção pode ser considerado como inicial, com o registro do modelo as-built BIM para operação. Essa escassa implementação ocorre devido a desafios tais como o alto esforço de modelagem/conversão de dados em objetos BIM, a necessidade de atualização de informações em BIM e o tratamento de dados, objetos e relações incertos no BIM que ocorrem em edifícios existentes [5].

No Brasil, é ainda pequeno o número de empresas que utilizam BIM em suas atividades de trabalho [6]. Este cenário deve se alterar com a instituição pelo governo federal brasileiro da Estratégia Nacional para Disseminação do BIM [7], com o intuito de aumentar a produtividade das empresas do setor e reduzir os custos de suas obras.

Neste contexto é que se insere a presente pesquisa: a representação física de uma edificação existente, no caso, o Instituto Maria, de maneira a subsidiar a realização de suas atividades de manutenção. O objetivo deste artigo é apresentar e discutir o processo de representação BIM da edificação, que vem sendo realizado, procurando identificar as facilidades e dificuldades que vêm sendo encontradas ao longo deste percurso.

\section{Enquadramento}

Para a representação física de uma edificação pode-se partir de um levantamento cadastral. Este serve para atestar, através de medições, o que existe construído em um lote ou terreno. Permite a obtenção de um cadastro contendo as características físicas da edificação existente com todos os seus elementos construtivos. O objetivo principal é a obtenção de um cadastro fiel ao que foi construído para realização de manutenções preventivas e futuras regularizações do imóvel, em função de novas reformas que possam ocorrer.

Conforme aponta Oliveira (2008 apud [8]), é importante manter a estruturação cadastral dos registros históricos. Uma vez que toda a estrutura original foi preservada, o seu resgate após uma eventual degradação, torna-se um tanto quanto mais simplificada. O levantamento, por sua vez, deve ser atualizado sempre que uma informação nova for obtida, para o sistema sempre continuar se alimentando de informações atuais.

O principal recurso manual utilizado para a realização do cadastro é a medição direta, que é tradicionalmente executada com o auxílio de instrumentos simples, como trenas, fios de prumos e níveis, em que são anotadas sobre os esboços do objeto a ser cadastrado as dimensões levantadas. Atualmente, é possível trabalhar com instrumentos de medição automatizados, como as trenas, níveis e goniômetros eletrônicos, que aumentam a precisão e reduzem o tempo de trabalho em campo. Além disso, existem outros métodos tecnológicos mais avançados para executar uma levantamento cadastral, como a Fotogrametria, Laser Scanning e entre outros. $\mathrm{O}$ uso de tecnologia no levantamento cadastral é uma parte importante pois "torna o processo de 
registro mais ágil, a gestão dos bens mais eficaz, e a preservação do patrimônio arquitetónico mais efetivo" [8].

A partir dos dados coletados em campo, pode-se utilizar o "BIM como tecnologia que lança mão de modelos paramétricos para fins de documentação e intervenção no patrimônio modernista" [9]. Com a finalidade de minimizar a ocorrência de erros e facilitar a visualização do projeto, o BIM tem sido cada vez mais requisitado dentro do estudo e execução do projeto com o intuito de se entregar um projeto da forma mais simples e eficiente [10].

Diferente do Computer Aided Design (CAD), que desenvolve cada projeto isoladamente buscando somente sua representação, o BIM é um sistema que compreende todas as fases do ciclo de vida de uma construção, sendo elaborado para armazenar todas as informações e representações do edifício de maneira integrada em um só arquivo, possibilitando uma maior acessibilidade aos dados e atualização das modificações realizadas ao longo do tempo [8].

O BIM pode incorporar uma gama de informações como, por exemplo, "da topografia, da implantação da construção, relações com a envolvente, dimensionamento, geometria e visualização espacial, materiais construtivos e suas propriedades, características físicas dos materiais que compõem os produtos, quantidades e custos, planificação de todo o processo, prazos, processos construtivos, diferentes instalações, sustentabilidade, etc." [11].

A utilização do BIM está sendo fundamental para a conservação das características originais e gestão das informações das edificações existentes, uma vez que contém ferramentas que conseguem representar através de modelos paramétricos e gráficos, pequenos detalhes da arquitetura da edificação, possibilitando uma maior proximidade do modelo com a realidade. Além disso, através da sistematização da documentação e da simulação virtual é possível inspecionar mudanças, programar futuras intervenções, identificar situações de emergência bem como planejar uma rotina de manutenção e gestão do edifício [12].

\section{Metodologia}

Para o alcance do objetivo proposto foram realizadas as seguintes etapas:

- Reconhecimento: conhecimento do espaço físico, análise da documentação existente;

- Levantamento: elaboração de formulário para levantamento em campo, medições in-loco, registro fotográfico;

- Modelagem: treinamento e acompanhamento em Revit, modelagem.

- Finalização: impressão para entrega à Instituição

A partir da realização da etapa de reconhecimento, as etapas seguintes foram sendo realizadas de maneira conjunta até a etapa de finalização.

\section{Caso de Estudo}

\subsection{Descrição}

O Instituto Maria (http://www.institutomaria.org/) é uma instituição filantrópica sem fins lucrativos que tem por objetivo oferecer de forma gratuita formação educacional e cultural às 
crianças desprovidas material e socialmente. O Instituto foi fundado em 19 de março de 1944 por Orvile Derby Dutra e Aracy Oliveira Dutra sendo hoje presidido pela filha do casal, Vânia Derby Dutra. Inicialmente funcionando como orfanato de meninas passou em 1973 a crecheescola. Hoje atende a 140 crianças na faixa etária dos 4 meses aos 5 anos e 11 meses de idade. As crianças são atendidas em um ambiente aconchegante realizando atividades que estimulam o seu desenvolvimento psicomotor acompanhados de alimentação balanceada além de assistência na área de saúde com médico e dentista. Como formação geral são oferecidas aulas de Informática, de Música, de Dança e de Teatro.

O Instituto está localizado no bairro São Mateus em Juiz de Fora/MG em meio a uma área verde possuindo $3.000 \mathrm{~m}^{2}$ de área construída composta por variados espaços, como por exemplo, salas de aula, biblioteca, lavanderia, banheiros, vestiários para funcionários, consultórios médico e odontológico, cozinha, refeitório, quadra coberta, etc, distribuídos em dois pavimentos (Figura 1).

Desde a sua fundação várias atividades de manutenção vêm sendo realizadas de maneira a manter as instalações em condições adequadas de uso e operação.

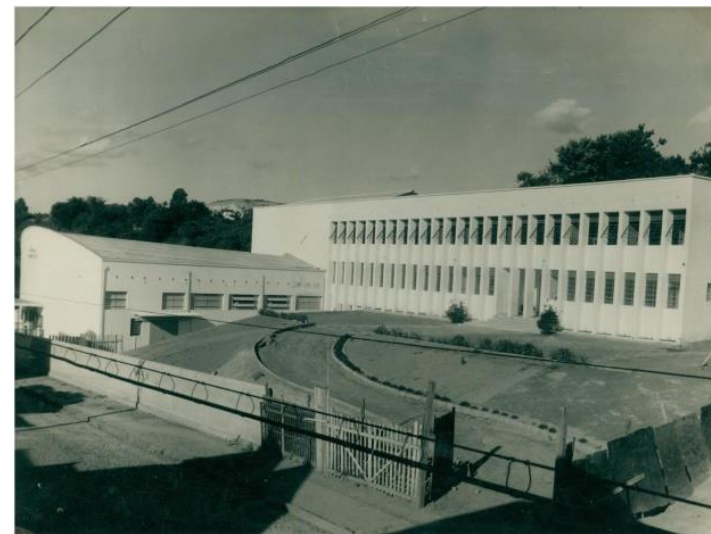

Época da construção [13]

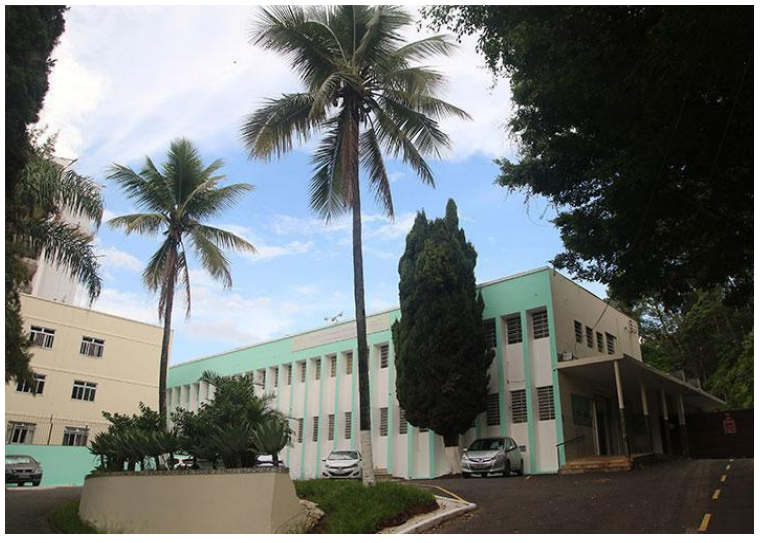

Atualmente [14]

Figura 1: Instituto Maria.

\subsection{Recolha de informação}

Para o levantamento das informações da edificação buscou-se inicialmente pelos projetos. Entretanto, o Instituto não dispõe dos projetos as-built da edificação, o que dificulta a gestão de sua manutenção. O último levantamento do espaço físico foi realizado em 2006 e sua representação física feita em papel vegetal. Desde este período diversas intervenções foram realizadas sem, entretanto serem registradas em planta.

Para ajudar no levantamento das informações a equipe desenvolveu um formulário a ser preenchido a mão com as dimensões e localização dos elementos e acabamentos existentes em cada ambiente da construção.

Com isso, a equipe formada pelo professor e sete alunos foi dividida em duplas e iniciou o levantamento do $1^{\circ}$ pavimento da edificação estabelecendo-se os espaços de trabalho de cada dupla. Neste dia, uma outra equipe, de outro projeto, também estava no local realizando o levantamento das patologias existentes na edificação. A não padronização de elementos da edificação como divisórias e esquadrias além da variedade de materiais de acabamento tornou o processo de levantamento das dimensões moroso. Desta maneira ficou decidido que seriam 
levantadas, em um primeiro momento, somente as dimensões (dos cômodos e elementos da construção) para posteriormente serem levantadas as demais informações do ambiente (material de acabamento e detalhes construtivos). Seguindo esta dinâmica a equipe retornou ao local outras duas vezes para completar o levantamento físico e registro fotográfico.

Posteriormente foram ainda realizadas mais algumas visitas ao local para verificação das medidas levantadas. Ao todo foram gerados 85 formulários referentes à 67 ambientes existentes na edificação. A maior parte dos ambientes está localizada no primeiro pavimento visto que existia no segundo pavimento, uma grande área referente à um guarda móveis, que hoje desativado, transformou-se em um galpão.

\subsection{Modelação}

Inicialmente, as informações levantadas em campo seriam utilizadas para realizar a representação gráfica da edificação utilizando-se do software CAD. Porém, por sugestão de um dos participantes da equipe, antigo coordenador do Grupo de Estudos e Práticas em BIM GEBIM/UFJF optou-se por utilizar o Revit e a sugestão foi prontamente aceita pela equipe.

O GEBIM/UFJF está inserido no Núcleo de Estudos e Projetos em Educação Tecnológica da Faculdade de Engenharia da UFJF (NETEC) e surgiu da necessidade de inovação no currículo dos cursos envolvidos no setor AEC (Arquitetura, Engenharia e Construção), prática já adotada anteriormente no NETEC, onde são estudados assuntos como o projeto de construção civil, BIM, gerenciamento de projetos e análise de riscos na construção civil. O GEBIM/UFJF tem suas atividades voltadas à pesquisa e à aplicação dos conceitos da Modelagem da Informação da Construção (BIM), com foco na produção e disseminação do conhecimento dessa plataforma na UFJF.

Entretanto, como no curso de Engenharia Civil da Universidade Federal de Juiz de Fora o uso do Revit ainda está restrito à somente algumas disciplinas, com poucos professores fazendo uso da ferramenta, nem todos os participantes dominavam o seu uso. Por isso, fez-se necessária a realização de um treinamento, de maneira a capacitar os alunos para a realização das atividades demandadas. Ele foi ministrado pelo coordenador do GEBIM e realizado no laboratório da Faculdade que possui o software instalado em suas máquinas, na versão educacional, no período de quatro horas. Neste treinamento os participantes puderam ter um contato maior com o software realizando um minicurso de capacitação que envolveu a introdução de conceitos básicos sobre BIM, definição, processos e ferramentas. E na parte prática, houve a introdução da modelagem arquitetônica no software Revit no qual desenvolveu-se um modelo de nível de detalhamento inicial.

A partir daí, na medida em que os dados do Instituto Maria foram levantados em campo eles eram transportados para o Revit. Este procedimento foi adotado de maneira que as inconsistências porventura encontradas, em virtude da grande área física a ser levantada, pudessem ir sendo verificadas e resolvidas ao longo do processo de representação, com o apoio do GEBIM.

No início da modelagem os alunos foram inserindo no modelo os dados por eles levantados inloco, trabalhando com os elementos disponíveis no software. Uma primeira versão obtida pode ser vista na Figura 2.

Na sequência, outros elementos foram também inseridos, como os pilares presentes na fachada frontal (conforme pode ser visto na Figura 1). Na medida em que o modelo foi sendo refinado, novos elementos precisaram ser criados, como por exemplo, meia parede, cortina de vidro, etc. Uma versão mais atualizada do modelo pode ser vista na Figura 3. 

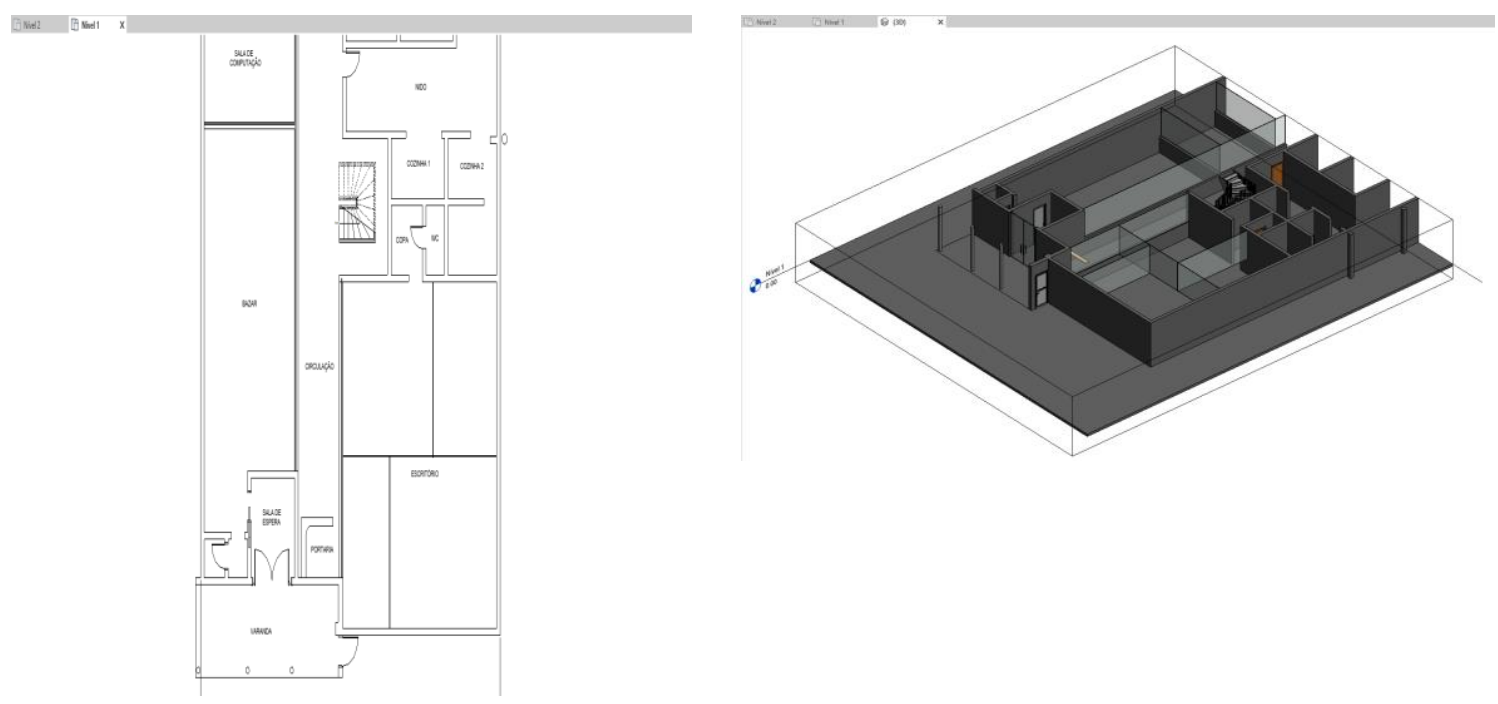

Figura 2: Modelagem inicial da edificação (2019).
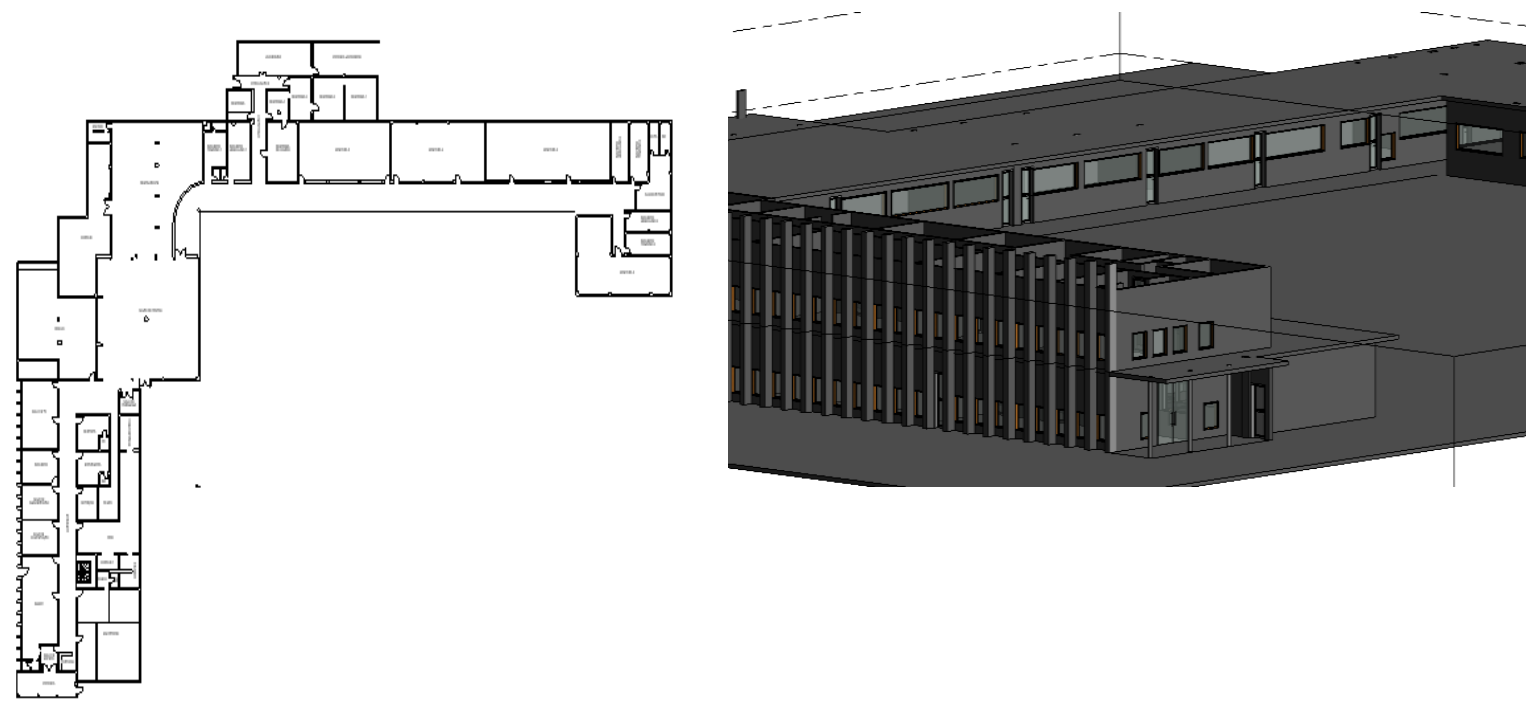

Figura 3: Modelagem final da edificação (2019).

\subsection{Resultados e discussão}

Ao longo do desenvolvimento do projeto diversas dificuldades e facilidades foram observadas. Como primeira dificuldade pode-se citar a metodologia utilizada para a elaboração do modelo. Como todos os alunos estavam trabalhando no mesmo modelo inserindo os seus dados, a gestão do trabalho compartilhado ficou comprometida. Por exemplo, as salas dos consultórios (que ficavam no meio do primeiro pavimento) só podiam ser implementadas depois que os responsáveis pelo detalhamento do corredor tivessem inserido suas paredes. Não se conseguiu criar ambientes isolados para depois serem interligados. Além disto, dois ou mais alunos não conseguiam trabalhar de forma simultânea no modelo. Deste modo foi estabelecida uma escala 
de trabalho para que as inserções de informações no modelo fossem feitas de forma sequencial e não simultânea.

No trabalho de modelagem em si foram identificadas dificuldades tais como a criação de alguns elementos como meia parede com vidro e cortina de vidro. Outras dificuldades demandaram aprendizagem, como por exemplo, fixação das paredes pelas cotas impedindo que suas dimensões fossem alteradas em virtude de inserção de novos ambientes. Além disto foram também observadas dificuldades para a ligação entre piso e laje, o detalhamento dos degraus de acesso existentes na fachada frontal, bem como a representação de algumas janelas e portas, devido ao formato irregular dos mesmos e a ausência de criação rápida de objetos históricos, que não ocorre quando se utiliza outros equipamentos tecnológicos, como o laser scanning. Uma outra dificuldade encontrada durante o desenvolvimento do modelo refere-se à espessura das paredes, que inicialmente foram adotadas de forma padronizada e ao final da representação do corredor do primeiro pavimento, os ambientes a esquerda que deveriam terminar na mesma posição dos ambientes a direita, não coincidiam, como na realidade ocorre. Isto demandou novas visitas e alguns retrabalhos, para a coleta e aplicação correta das dimensões no modelo. Em que pese as dificuldades encontradas, algumas facilidades foram também identificadas. Pode-se citar a facilidade para realizar a representação do projeto utilizando-se dos elementos preexistentes que se mostrou nítida, com otimização do tempo dispendido. Além disto, foi também observada uma maior facilidade para alteração das medidas dos objetos (tanto em duas como em três dimensões).

Porém, ao final do levantamento pode-se dizer que a maior vantagem observada refere-se ao processo de ensino aprendizagem. Os alunos participantes do projeto puderam se apropriar de novos conhecimentos aplicando-os nas atividades realizadas no projeto, bem como levando-os à aplicação em novos contextos do curso.

\section{Considerações finais}

O caso de estudo realizado permitiu que fossem verificadas vantagens bem como algumas dificuldades na utilização do BIM para realização de levantamento cadastral de uma edificação. No que se refere ao Revit, observa-se seu potencial como instrumento para a gestão da manutenção e preservação das edificações, auxiliando os gestores na fase de uso e operação e manutenção a partir do compartilhamento de dados com outros softwares. Principalmente porque o modelo construído pode ser complementado com as informações referentes aos materiais de construção o que permitiria, por exemplo, a extração de quantitativos de materiais e previsão orçamentária para a recuperação do conjunto.

Além disso, no que se refere à preservação do edifício, observa-se a necessidade de integração de informações que, muitas vezes, encontram-se distribuídas em registros realizados algumas vezes à lápis em papel manteiga, ou apenas em fotos e desenhos artísticos. Com isso, o software Revit mostrou grande potencial em permitir que muitos profissionais atuem no modelo do edifício, facilitando o processo colaborativo. E, por último, a realização da maquete eletrônica proporcionou um maior entendimento do ambiente físico que está sendo representado. Com isso, todas as vistas puderam ser observadas, bem como os cortes sobre o modelo.

No entanto, diante das perspectivas dispostas, conclui-se que o Revit apresenta algumas dificuldades, mas que podem ser minimizadas devido às facilidades possibilitadas que foram importantes para o desenvolvimento do presente estudo. Pode-se citar a otimização do tempo 
se comparada à plataforma CAD, para a inserção de paredes, portas e janelas. Além disto, no CAD o primeiro e o segundo pavimentos são dispostos separadamente e não existe a possibilidade de se gerar uma planta tridimensional. Esta traz uma facilidade ao permitir visualizar o que está sendo feito e localizar possíveis erros.

Ao final pode-se também citar os benefícios obtidos com o uso da ferramenta no que diz respeito ao processo de ensino-aprendizagem. A continuidade do projeto prevê a alimentação do modelo com as informações referentes às patologias identificadas bem como a modelagem das demais disciplinas de projeto de maneira a colaborar com a manutenção e preservação do Instituto.

\section{Referências}

[1] J. S. Terror, O Granbery e sua imagem arquitetônica. Juiz de Fora, 2002.

[2] M. A. El-Haram e M. W. Horner, "Factors Affecting Housing Maintenance Cost," Journal of Quality in Maintenance Engineering, vol. 8, n. 2, pp. 115-123, Junho de 2002. doi: 10.1108/13552510210430008.

[3] C. Eastman et al., BIM Handbook: a guide to building information modelling for owners, managers, designers, engineers and contractors. $2^{\text {nd }}$. ed. New York: John Wiley \& Sons, 2011.

[4] J. K. W. Wong, J. Ge e S. X. He, "Digitisation in Facilities Management: a literature review and future research directions," Automation in Construction, vol. 92, pp. 312-326, August 2018. doi: 10.1016/j.autcon.2018.04.006.

[5] R. Volk, J. Stengel e F. Schultmann, "Building Information Modelling (BIM) for Existing Buildings: literature review and future needs," Automation in Construction, vol. 38, pp. 109-127, March 2014. doi: 10.1016/j.autcon.2013.10.023.

[6] Ministério da Economia Indústria, Comércio Exterior e Serviços. Governo Federal Lança Estratégia Para Promover a Inovação na Indústria da Construção. 2018. Available in: <http://www.mdic.gov.br/index.php/noticias/3296-governo-federal-lanca-estrategia-parapromover-inovacao-na-industria-da-construcao>. Acess: 20 set. 2018.

[7] Brasil, Decreto $\mathrm{n}^{\circ}$ 9.377, de 17 de maio de 2018, que institui a Estratégia Nacional de Disseminação do Building Information Modelling, Diário Oficial da União, Brasília, 17 may 2018.

[8] M. M. A. Tolentino e B. B. L. Feitosa, "A Utilização de Tecnologias Digitais na Documentação do Patrimônio Arquitetônico," in III Seminário Internacional Sobre Documentação do Patrimônio Arquitetônico Com o Uso de Tecnologias Digitais (2014), João Pessoa, Paraíba, Brasil, 2014.

[9] R. A. Paiva, B. H. N. Diógenes e D. R. Cardoso, "Futuro do Pretérito: BIM e Documentação Digital da Arquitetura Moderna em Fortaleza," in VII Encontro Brasileiro de Tecnologia de Informação e Comunicação na Construção (2015), Recife, Pernambuco, Brasil, 2015.

[10] C. L. Canuto, L. R. Moura e M. S. Salgado, "Tecnologias Digitais e Preservação do Patrimônio Arquitetônico: Explorando Alternativas," PARC Pesquisa em Arquitetura e Construção, vol. 7, n. 4, pp. 252-264, December 2016. doi: 10.20396/parc.v7i4.8647456. 
[11] R. Giollo, M. J. F. Silva e P. Couto, "Reabilitação de um Edifício Público: Contributo para a Interoperabilidade Entre BIM e PRONIC," in I Congresso Português de Building Information Modelling (2016), Guimarães, Portugal, 2016. doi: 10.5281/zenodo.166758.

[12]M. J. L. Venâncio, "Avaliação da Implementação de BIM - Building Information Modeling em Portugal," Dissertação de Mestrado, Departamento de Engenharia Civil, Faculdade de Engenharia da Universidade do Porto, Porto, Portugal, 2015. 11

[13] Tribuna de Minas. Available: https://tribunademinas.com.br/noticias/cidade/23-032019/instituto-maria-completa-75-de-historia-com-mais-de-dez-mil-criancasatendidas.html. Acess: 06 Jun 2019.

[14] Insituto Brasileiro de Geografia e Estatística. Available https://biblioteca.ibge.gov.br/index.php/biblioteca-catalogo?id=445394\&view=detalhes. Acess: 06 Jun 2019. 